\title{
Páginas web sobre exposiciones virtuales de fondo antiguo: recopilación y análisis
}

\author{
Por José Luis Herrera Morillas
}

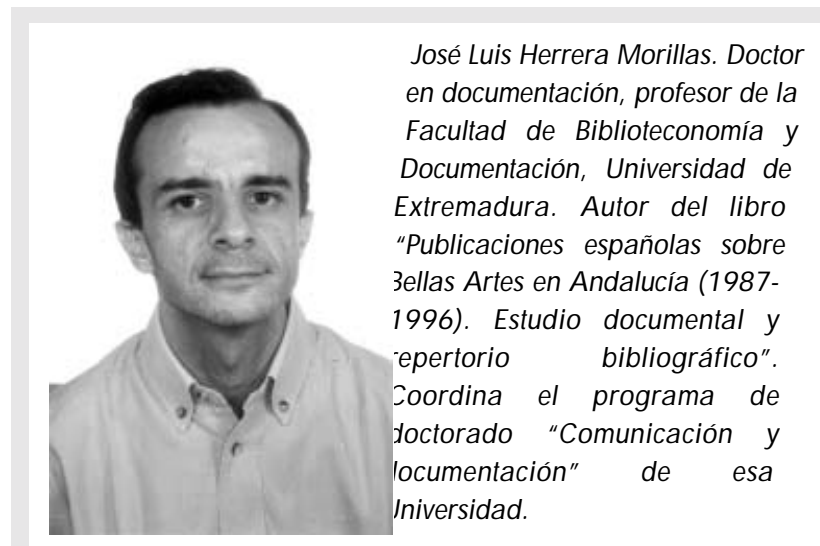

\begin{abstract}
Resumen: Este trabajo se centra en exposiciones virtuales de libros antiguos, organizadas por distintas instituciones y redes bibliotecarias de Europa (Rebiun -Red de bibliotecas universitarias españolas-, Universidad de Cambridge, bibliotecas de la Universidad de Barcelona, Universidad de Málaga, Universidad de la Laguna, Universidad de Glasgow, Universidad Complutense, Universidad de Castilla La Mancha, bibliotecas nacionales de Europa, Biblioteca Universitaria de Liverpool, etc.), Canadá (Biblioteca Nacional de Canadá, Universidad Simon Fraser, Universidad British Columbia, etc.) y EUA (Biblioteca del Congreso, Biblioteca Harold B. Lee, Biblioteca de la Universidad de Pennsylvania, Universidad de Harvard, etc.). Las estudiamos analizando aspectos como el diseño, la estructura y los contenidos. Proponemos una metodología de análisis de este tipo de web, que es la que se ha aplicado en nuestro trabajo.

Palabras clave: Exposiciones virtuales, Fondo antiguo, Libros antiguos, Análisis de web, Internet.
\end{abstract}

Title: Virtual exhibitions of antiquarian books: a compilation and analysis

Abstract: This work highlights virtual exhibitions of antiquarian books organised by individual institutions and library networks in the United States (Harold B. Lee Library, Library of Congress, Harvard University, University of Pennsylvania Library...), Canada (National Library of Canada, Simon Fraser University, University of British Columbia...) and Europe (Barcelona University Library, Castilla La Mancha University Library, Madrid's Complutense University Library, Málaga University Library, Cambridge University, Rebiun -Spanish university libraries network-, Laguna University Library, Glasgow University Library, European national libraries, Liverpool University Library). An analysis is made of these web sites, including their design, structure and contents. Finally, a method is proposed for analysing this type of web, based on that used in this study.

Keywords: Virtual exhibitions, Antiquarian books, Rare book collections, Web. Analysis, Internet.

\section{Introducción}

INTERNET VA CRECIENDO en aportaciones y aplicaciones para las bibliotecas y el patrimonio bibliográfico con la producción y difusión tanto de recursos como de servicios a través de la Red. El libro antiguo está siendo uno de los campos más favorecidos. Las características y circunstancias que lo rodean lo hacen idóneo para someterlo a los procesos que hoy en día permiten las nuevas tecnologías, entre los que destaca la digitalización "que no sólo está facilitando un acceso directo al texto, sino que está contribuyendo a su pre- servación y conservación al evitar la manipulación del original".

De este modo, el estudio y acceso del libro antiguo que "ha estado siempre supeditado a la edición de facsímiles o a la consulta in situ de los textos"2 se ha revolucionado con la implantación y avance de las nuevas tecnologías. Junto a estos aspectos hay otros que explican el hecho de que estas obras sean objeto preferente de este tipo de muestras. Entre ellos destacamos su valor artístico (con frecuencia van enriquecidos con ilustraciones, grabados o encuadernaciones) y la necesidad de difusión de estas co- lecciones, para la cual las exposiciones son un excelente recurso.

En el caso que nos ocupa, las "exposiciones virtuales", las obras expuestas en muy pocos casos aparecen totalmente digitalizadas, lo cual es más propio de otro tipo de actuaciones como por ejemplo las publicaciones en cd-rom. Por lo tanto podemos decir que difundir las colecciones, más que facilitar el acceso completo a ellas, es el objetivo principal de estos proyectos en línea.

La finalidad de este artículo ha sido localizar "exposiciones virtuales" sobre el fondo antiguo de diferentes bibliotecas y coleccio- 
nes para analizarlas y dar a conocer, entre otros aspectos, su contenido y dirección para facilitar su consulta. También proponemos una metodología de análisis de este tipo de web que es la que se ha aplicado en nuestro trabajo.

\section{Metodología}

La primera tarea ha consistido en localizar las páginas con esta temática, hallando en total 71. Están representadas desde exposiciones pequeñas y de escaso calado hasta muestras que reúnen colecciones de gran envergadura. Pero, aplicando los parámetros de calidad sobre evaluación de recursos digitales $^{3}$ propuestos por Lluís Codina, podemos decir que todas tienen una información adecuada al tema de nuestro interés y tratada de forma rigurosa; presentan una buena navegación y recuperación, permitiendo recorrer la estructura de la web sin sensación de pérdida; la lectura y visualización resultan agradables, conteniendo imágenes con una adecuada relación figura/fondo ${ }^{4}$.

Nuestro criterio ha sido reunir en este trabajo todas las muestras virtuales localizadas que tengan por contenido colecciones de libros antiguos, y en todas ellas el término "exposición" aparece casi siempre en el título o en los textos introductorios. Hemos dejado fuera aquellas que, aunque relacionadas con el tema, se centran exclusivamente en manuscritos, cartografía o encuadernaciones, así como las que no están concebidas como exposiciones o catálogos virtuales puesto que son más bien páginas divulgativas de los fondos de bibliotecas, de colecciones, etc.

La fase siguiente ha consistido en el estudio de las páginas, realizado sólo con 10 exposiciones para no extendernos en exceso ${ }^{5}$. Previamente hemos diseñado un esquema de análisis, que se inicia con el estudio del contenido: iden- tificamos en primer lugar algunos datos básicos como la temática de la muestra, el volumen de obras expuestas, el motivo por el cual se ha llevado a cabo, el lugar de celebración, etc.

\section{«Los textos comple- tos digitalizados de obras antiguas son más propios de las publicaciones en cd- rom»}

Con posterioridad nos detenemos en el análisis del título y en la portada; por ésta entendemos la parte de la web que incluye los datos que identifican la exposición y su contenido, que suele estar diseñada a modo de portada de un catálogo de exposición impreso. Comentamos además aspectos que hacen referencia a si está o no formada por una página independiente, información que refleja, etc.

Seguidamente abordamos un elemento que centra especialmente nuestro interés - lo consideramos el núcleo central de estos documentos-: el catálogo de obras expuestas. Nos detenemos en describir, por ejemplo, la forma en que se organiza la información, la redacción de los asientos, los elementos que los componen o las imágenes digitalizadas de las obras ${ }^{6}$.

Por último, y debido a que es frecuente que incluyan además otro tipo de información, dedicamos una sección para otros elementos, en la que señalamos y describimos si contienen información introductoria, textos de presentación, enlaces a otros recursos relacionados, direcciones de contacto, índices, etc. El segundo apartado de este análisis lo hemos dedicado al diseño que presentan, para reflejar y comentar cuestiones relacionadas con la estructura y organización de los contenidos.
Estos dos apartados los hemos establecido después de una detenida lectura y visualización así como su comparación con los catálogos impresos de las exposiciones presenciales. Hemos comprobado que la composición e información que presentan es muy similar a las de las "exposiciones virtuales" recopiladas.

La información de cada web, presentada en el apartado siguiente, la hemos distribuido según el siguiente esquema: título, url, lengua, fecha de consulta, institución organizadora, contenido (título, portada, catálogo de obras, otros elementos) y diseño.

\section{Análisis de las webs}

1. Antiquària exposició: la dermatologia al fons de la reserva de la biblioteca

\section{http://www.bib.ub.es/www4/4expo} 00.htm

-Institución organizadora: Facultad de Medicina, Universitat de Barcelona.

—Lengua: catalán.

-Fecha de consulta: 01-09-01.

-Contenido: está dedicada a obras de dermatología y abarca una muestra del fondo antiguo de la sección de medicina de la biblioteca de la Universitat de Barcelona. En ella se pueden contemplar libros de celebridades de esta disciplina como Joan Giné, Alfred Hardy o Morez Kaposi, y se realizó en conmemoración del día de Sant Jordi de 2000. La exposición presencial tuvo lugar en la biblioteca de la universidad desde el 26 de abril al 15 de mayo de 2000 .

La dermatología es "una especialidad muy documentada en este centro universitario, que cuenta, por ejemplo, con la Colección Vilanova formada por 1.370 ejemplares, procedentes de la Cátedra de Dermatología de la época en que 


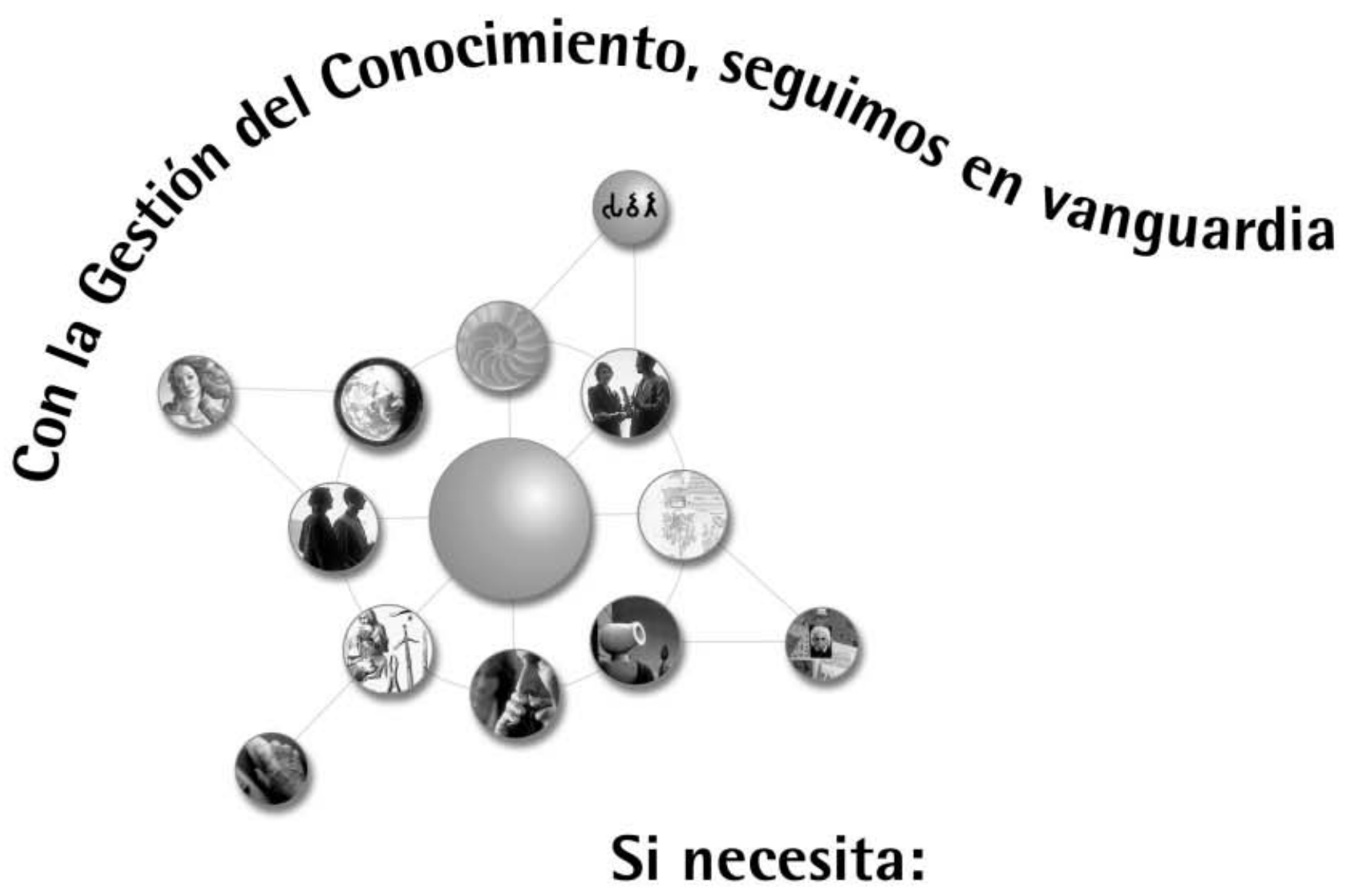

- Un programa de tercera generación, amigable, con acceso vía web, protocolo Z39,50

- Gestionar todo tipo de documentos, acceder al documento original, visualizar imágenes digitalizadas y vídeos.

- Un sistema abierto que pueda ajustarse a sus necesidades: añadir nuevos campos y crear nuevas bases de datos.

- Ofrecer de manera rápida su información en entorno web (Intranet y/o Internet).

- Un sistema ágil para la entrada de datos y que le permita capturar información de fuentes distintas.

- Una gestión integrada de su biblioteca digital.

\section{Le ofrecemos}

Estamos certificados

\section{un abanico de soluciones.} en calidad ISO 9002

por Bureau Veritas Quality International en:

- Consultores en recursos de información

- Gestión del conocimiento

- Intranet/Extranet/Internet

- Edición electrónica

- Suscripciones a bases de datos y a revistas electrónicas (http://informame.doc6.es)

- Programas de gestión documental

- Cursos de formación

Mallorca, 272, planta 3

08037 Barcelona

Tel. 932154313

Fax 934883621
Comandante Zorita, $8,2^{\circ} 4^{\mathrm{a}}$ 28020 Madrid

Tel. 915535207

Fax 915346112

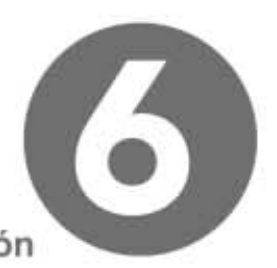

mail@doc6.es www.doc6.es 


\section{Webgrafía. Relación completa del resto de exposiciones localizadas}

1492: an ongoing voyage.

Institución: Library of Congress.

http://lcweb.loc.gov/exhibits//492/

Accent on images: an exhibit of the libraries of the Claremont Colleges. Institución: Claremont Colleges. http://voxlibris.claremont.edu/sc/events/ accent/Lo_Accentonlmages.htm

In Aedibus Aldi: the legacy of Aldus Manutius and his press. Institución: Brigham Young University. http://library.byu.edu/ aldine/

Aldus Pius Manutius: publisher of Renaissance Venice. Institución: Simon Fraser University. http://www.lib.sfu.ca/proj/aldus.htm

American treasures of the Library of Congress.

Institución: Library of Congress. http://www.loc.gov/exhibits/treasures/

Archives and special collections: a treasury of the human spirit. Institución: University of Connecticut. http://www.lib.uconn.edu/DoddCenter/ ascexh I.html

The art of the book: rare printed books from the University of Liverpool Library.

Institución: University of Liverpool. http://sca.lib.liv.ac.uk/exhibitions/bookart.htm

Aspects of the victorian book. Institución: British Library. http://www.bl.uk/collections/early/victorian/ intro.html

Aureum corpus. Cinco siglos de libros ilustrados.

Institución: Museo Frederic Marès de Barcelona.

http://www.uoc.es/humfil/aureum/index_es. html

L'aventure des écritures: matières et formes.

Institución: Bibliothèque nationale de France.

http://www.bnf.fr/web-bnf/pedagos/ dossisup/index.htm

The Berlin Collection: being a history and exhibition of the books and manuscripts purchased in Berlin in I89। for the University of Chicago. Institución: University of Chicago. http://www.lib.uchicago.edu/Liblnfo/ Libraries/SpCl/ExhibitionCatalogues/ BerlinCollection/
La biblioteca del Quijote. Institución: Biblioteca de la Universidad de Castilla La Mancha http://www.biblioteca.uclm.es/cervantes/ cervantes.htm

Bibliotheca Canadiana: a historical survey of Canadian bibliography / Étude historique de la bibliographie canadienne.

Institución: McGill University. http://www.library.mcgill.ca/rarebook/ bibcanho.htm

Bibliotheca schoenbergensis: an exhibition from the collection of Lawrence J. Schoenberg. Institución: University of Pennsylvania. http://www.library.upenn.edu/special/ gallery/schoenberg/schoenberg.html

A brave bad man: Oliver Cromwell, 1599-1658.

Institución: Cambridge University. http://www.lib.cam.ac.uk/Exhibitions/ Cromwell/cromwell.htm

The damned art. Institución: Glasgow University Library. http://special.lib.gla.ac.uk/exhibns/ damnedart/index.html

Don Quixote de la Mancha. Institución: Johns Hopkins University. http://quixote.mse.jhu.edu/

Drapetomania, a disease called freedom: an exhibition of 18th-, 19th-, and early 20th-century material culture of the African experience in the Americas from the collection of Derrick Joshua Beard.

Institución: Broward County Library. http://www.broward.org/lii / 3000.htm

Dresden: treasures from the Saxon State Library.

Institución: Library of Congress. http://www.loc.gov/exhibits/dres/ dresintr.html

Etienne-Louis Boullé. Institución: Bibliothèque nationale de France.

http://www.bnf.fr/pages/expos/boullee/ index.htm

Apollo.

The face of the moon: Galileo to Institución: Linda Hall Library. http://www.lindahall.org/pubserv/hos/ moon/cover.htm
From $A$ to $Z$ : an exhibition of $A B C$ books selected from the John $\mathrm{O}$. $\mathrm{C}$. McCrillis Collection.

Institución: Trinity College, Hartford, Connecticut. http://www.trincoll.edu/depts/library/ watkinson/exhibits/AtoZ/abc.html

From alchemy to chemistry: five hundred years of rare and interesting books.

Institución: University of Illinois at Urbana-Champaign.

http://www.scs.uiuc.edu/ mainzv/exhibit/ index.htm

From written word to the printed text: the transmission of Jewish tradition.

Institución: University of Pennsylvania. http://www.cjs.upenn.edu/archive/// Preface.htm

A great assemblage: an exhibit of judaica.

Institución: Yale University.

http://www.library.yale.edu/exhibition/ judaical

Guido Mazzoni pamphlet collection.

Institución: Duke University.

http://scriptorium.lib.duke.edu/mazzoni/ exhibit/

Gutenberg and beyond: books, libraries, and changing technology. Institución: Georgetown University. http://gulib.lausun.georgetown.edu/dept/ speccoll/bkex $96 . \mathrm{htm}$

The Gutenberg years: anniversaries of printing from 1540 to the present. Institución: British Library. http://www.bl.uk/collections/epcl gutenberg/overview.html

The illustrated book, 1780-1830: selected from the collection of Harris N. Hollin.

Institución: University of Pennsylvania. http://www.library.upenn.edu/special/ gallery/hollin/index.html

Incunabula, hebraica \& judaica. Five centuries of hebraica and judaica, rare bibles, and hebrew incunables from the Jacob M. Lowy collection. Institución: National Library of Canada. http://www.nlc-bnc.calincunab/

Jesuits and the sciences, 1540 1995 . 
Institución: Loyola University of Chicago. http://www.luc.edu/libraries/science/jesuits/ index.html

Det Kongelige Bibliotek: treasures from the Royal Library / Klenodier fra Det kgl. Bibliotek.

Institución: Kongelige Bibliotek/Royal Library, Dinamarca.

http://www.kb.dk/kultur/expo/klenod/

Lands of opportunity: books of the states.

Institución: University of Delaware. http://www.lib.udel.edu/ud/spec/exhibits/ lands/

Living words and luminous pictures: 12 medieval manuscripts in the Royal Library-Copenhagen. Institución: Kongelige Bibliotek/Royal Library, Dinamarca.

http://www.kb.dk/elib/mss/mdrl

index-en.htm

Ludolph van Ceulen en de Berekening van het Getal Pi.

Institución: Universiteit Leiden. http://www.etcl.nl/bc/tentoonstelling/pi/ inhoud.htm

Mayo Foundation libraries 90th anniversary exhibit: anatomy books from the bequest of Dr. Anthony H. Kelly. Institución: Mayo Medical Libraries. http://www.mayo.edu/medlib/lib_exhibit/ index.html

The most of special collections. Institución: University of Virginia. http://www.lib.virginia.edu/exhibits/most/

Musicke of sundrie kindes. An exhibition from the Euing music collection: originally displayed II January- I8 February 1978.

Institución: Glasgow University Library. http://special.lib.gla.ac.uk/exhibns/music/ musickex.html

Naissance de la culture francaise: trésors de la Bibliothèque nationale de France.

Institución: Bibliothèque nationale de France.

http://www.bnf.fr/loc/bnf000I.htm

Of the incomparable treasure of the Holy Scriptures: an exhibit of historic Bible-related materials from the collection of the Andover-Harvard Theological Library.

Institución: Harvard University. http://www.hds.harvard.edu/library/ exhibitb/index.html
La page: l'aventure des écritures. Institución: Bibliothèque nationale de France.

http://www.bnf.fr/pages/pedagos/page/ index.htm

Perennial pages: an exhibition of flower illustration in books since the Renaissance: Glasgow University Library, 13 May-26 August 1995. Institución: Glasgow University Library. http://special.lib.gla.ac.uk/exhibns/ perenniallindex.html

Picturing childhood: illustrated children's books from the University of California collections, I550-1990.

Institución: University of California at Los Angeles.

http://www.library.ucla.edu/libraries/ special/childhoodlindex.htm

Printing in England from William Caxton to Christopher Barker. Institución: Glasgow University Library. http://special.lib.gla.ac.uk/exhibns/printing/ index.html

Printing: Renaissance and Reformation.

Institución: University of South Carolina. http://www.sc.edu/library/spcoll/sccoll/ renprint.html

Private passions, public legacy: Paul Mellon's Personal Library at the University of Virginia Institución: University of Virginia. http://www.lib.virginia.edu/exhibits/mellon/

Religion and the founding of the American Republic. Institución: Library of Congress. http://www.loc.gov/exhibits/religion/

Romance language acquisitions in early printed collections: rare books and music reading room exhibition. Institución: British Library. http://www.bl.uk/collections/epc/galileo.html

Scottish thought \& letters in the eighteenth century Institución: Glasgow University Library. http://special.lib.gla.ac.uk/exhibns/scottish/ index.html

Scrolls from the Dead sea. The ancient library of Qumran and modern scholarship.

Institución: Library of Congress. http://www.ibiblio.org/expo/deadsea.scrolls. exhibit/intro.html

The Thomas Murray Collection. Institución: University of British Columbia. http://www.library.ubc.ca/spcoll/murray/ default.html

The Tibetan book of the dead: literature and artwork on prayer, ritual, and meditation from the religious traditions of Tibet, India and Nepal. Institución: University of Virginia. http://www.lib.virginia.edu/exhibits/dead/

Tous les savoirs du monde et le cahier pédagogique de l'exposition. Institución: Bibliothèque nationale de France.

http://www.bnf.fr/web-bnflexpos/savoirs/ index.htm

Treasures of the APS (American Philosophical Society). Institución: American Philosophical Society.

http://www.amphilsoc.org/library/exhibits/ treasures/

A treasury of the human spirit: an exhibition of books and manuscripts from archives \& special collections. Institución: University of Connecticut. http://www.lib.uconn.edu/DoddCenter/ ascexhl.html

Les très riches heures du Duc de Berry. Institución: WebMuseum. http://metalab.unc.edu/wm/rh/

The University of Waterloo Library Seagram collection. Institución: University of Waterloo. http://www.lib.uwaterloo.ca/seagrams/

Women writers: an exhibitions of works from the $17^{\text {th }}$ Century to the presents. Institución: University of North Texas. http://www.library.unt.edu/rarebooks/ exhibits/women/default.asp

World treasures of the Library of Congress. Institución: Library of Congress. http://www.loc.gov/exhibits/world/

You shall tell your children (Ex. 13.8): the passover haggadah in the Yale University Library collections. Institución: Yale University. http://www.library.yale.eduljudaical exhibits/haggadah/

La Universidad Complutense a través de sus libros: 500 años de la bula cisneriana.

Institución: Biblioteca de la Universidad Complutense de Madrid. http://www.ucm.es/BUCM/frames0I.htm 
fue dirigida por el profesor Xavier Vilanova i Montiu (1947-1965)"”.

Se exponen 30 obras publicadas desde el siglo XVI hasta la primera mitad del XX seleccionadas según la importancia de los autores $\mathrm{y}$, en algunos casos, por el interés de las ilustraciones. En la versión virtual se han escogido 6 libros de los que se incluyen 7 imágenes que reproducen ilustraciones de enfermedades. Esta exposición es un ejemplo de las dedicadas a una sola institución con una colección especializada en una determinada materia y de las que la muestra online es más reducida que la presencial.

El título reúne expresiones que subrayan que estamos ante las obras de más valor y antigüedad de la biblioteca y por tanto apropiadas para formar parte de una exposición de estas características.

La sección dedicada al catálogo de obras incluye de cada publicación: ilustraciones, autor, título, lugar, editor, año, signatura y texto sobre el autor y la obra.

Otros elementos interesantes serían: un texto de presentación general sobre el origen y contenido de la exposición así como otro apartado para la bibliografía consultada.

—Diseño: la exhibición está contenida en una sola página. Se inicia con los datos que configuran la portada (figura 1), organizados según la siguiente composición: en un recuadro gris el título en blanco y en la parte superior, con letras rojas, "Sant Jordi 2000".

Se reproduce la portada de la obra de J. L. Alivert. Clinique de l'Hôpital Saint Louis, ou traité complet des maladies de la peau. Paris: chez B. Cormon et Blanc, 1833. También se muestra el resto de la información sobre la exposición (día, lugar, horario y motivo de la exposición). A continuación se incluye el texto de presentación general que da paso a las obras catalogadas: los registros están formados por las referencias bibliográficas en color verde azulado, la signatura (en rojo) y los textos descriptivos en negro, con letras de menor tamaño. Se reproducen varias ilustraciones de cada libro y el catálogo se cierra con la sección dedicada a la bibliografía consultada.

\section{Creating French culture:} treasures from Bibliothèque nationale de France

http://www.loc.gov/exhibits/bnf/

-Institución responsable: $L i$ brary of Congress.

—Lengua: inglés.

-Fecha de consulta: 01-10-01.

-Contenido: estamos ante una exposición que recorre la historia y cultura francesa desde Carlomagno hasta Charles de Gaulle, bajo el prisma de cerca de 200 obras de gran valor artístico y bibliográfico -fundamentalmente libros y documentos, pero también otros objetos como pinturas, monedas, etc.cedidas por la $B N F$ a la $L o C$. En la exposición virtual se realiza una selección de todas las obras y en total se muestran 67. Es representativa del modelo de exposición basada en ilustrar un tema histórico con distintos objetos, pero con mayor porcentaje de obras de carácter bibliográfico.

\section{«Las obras expues-} tas en muy pocos casos aparecen digitalizadas en su totalidad»

En el título se incluye el término "tesoros", muy utilizado en este tipo de eventos, lo que habla del carácter erudito y patrimonial que rodea a muchas de estas muestras. En primer lugar observamos la portada (figura 2) en una página en la que se incluye el índice general, una ilustración, accesos a una encuesta, a la página principal de la $L o C$ y a la de sus exposiciones, incluyendo también una dirección de contacto.

En lo que respecta al catálogo de obras está organizado en los siguientes apartados:

a. Monarcas y monasterios: dedicado al conocimiento y poder en la Francia medieval. Se subraya el auge que alcanza el estudio y elaboración de los textos religiosos en la época carolingia, destacando los monasterios de San Denis, Corbic y Cluny.

b. La trayectoria del Absolutismo: basado en la historia política y cultural de Francia durante el periodo en el que tienen lugar acontecimientos como la Reforma protestante: 1498-1661.

c. El auge y caída del Absolutismo monárquico: centrado en el florecimiento artístico, literario y científico durante el reinado de Luis XIV.

d. Desde el Imperio a la Democracia: incluye la etapa englobada entre 1799 hasta la actualidad.

De cada obra se recoge la siguiente información: autor, título, lugar de publicación, cronología, localización, texto explicativo y al menos una imagen digitalizada, contabilizándose hasta un total de 76 extraídas de códices y manuscritos iluminados, libros, mapas, grabados así como otras piezas (monedas, camafeos o encuadernaciones). Otros elementos presentes son introducción, conclusión y agradecimientos.

—Diseño: todas las páginas que conforman este documento tienen en común los siguientes rasgos: el color azul del fondo, sobre el que superpone un gran rectángulo blanco que es la superficie en la que se dispone la información fundamental de cada página; los títulos se sitúan en la parte de arriba 
3)

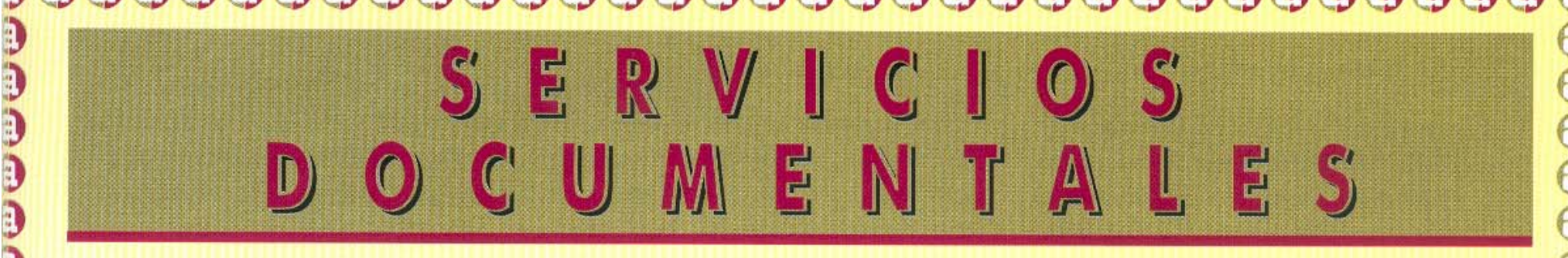

3

SERVICIOS EXTERNOS

A SU MEDIDA

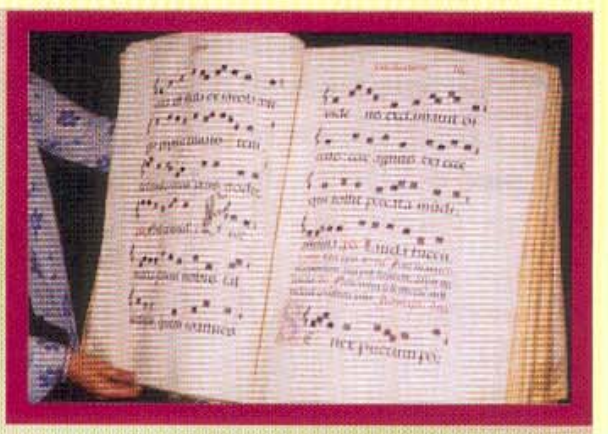

DHBLTECMS

- CATALOGACIÓN Y CONUERSIÓN RETROSPECTIVA

-DESGRIPEIÓN E INTEGRACIÓN DE FONDO ANTIEUO

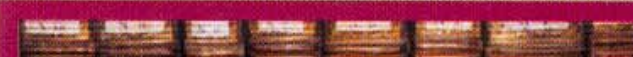

1

ABANA LE OFRECE

AMPLIA EXPERIENCIA

EN AUTOMATIZACIÓN

DE BIBLIOTECAS,

ARCHIVOS, MUSEOS

Y CENTROS DE

DOCUMENTACIÓN

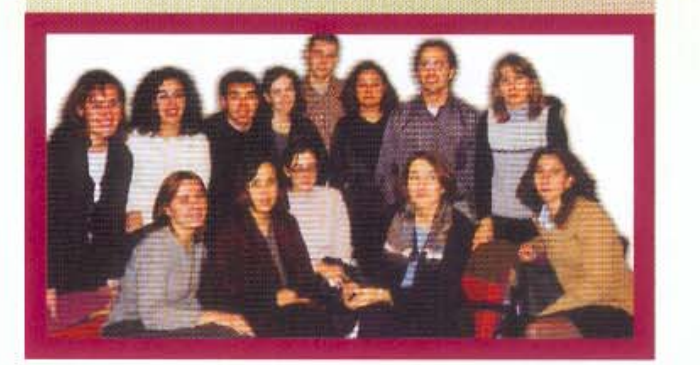

-PROCESO TÉENICO Y

TAREAS AUXILIARES

-MRCHIUOS HISTÓRLCOS

Y MอMINISThMTIUอง

- IDENTIFICACión

Y AMÁLISIS DE SERIES

- oreanización,

GLASIFICACIÓN Y GESTIÓN

-114) EOS

-REVISION DE REgISTROS

IMFORMATIZADOS

-automatización de

ELEMENTOS DOCUMENTALES

- InVEntario / catalogación DIRECTA

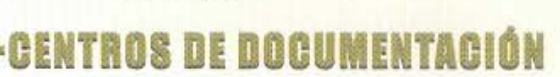
- GESTIÓN DE GONTEMIDOS -ENRIQUEEIMIENTO DE SU BASE DE DATOS -INDizaeIÓN DE DOCUMENTOS

-Disero, anabneión y CALIDAD HUMANA AL SERVICIO DIQITALIRIÓN DE DATOS

\section{UN EQUIPO DE}

DE SU INFORMACIÓN"

PROFESIONALES

ESPECIALIZADOS

QUE LE AYUDARÁN

A GESTIONAR MEJOR

SU INFORMACIÓN

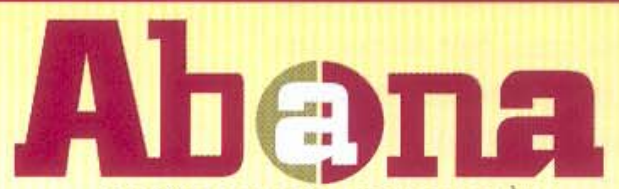

SISTEMAS DE INFORMACIÒN

C/ Santa Saturnina, 8 - Bajo B 28019 - Madrid

Teléfono: 91 5602088 Fax: 914695996 info@abana.es -www.abana.es

ค 
sobre el fondo azul. El índice general se reproduce en la sección superior e inferior de la zona blanca. En la inferior, además, se presentan los enlaces a la página principal de la $L o C$ y a su página de exposiciones, incluyendo también la dirección de contacto.

En la portada (figura 2) la superficie blanca va ocupada por el índice general en forma de columna y una ilustración de uno de los libros expuestos: Le voyage de gênes de Jean Marot.

Cada apartado del catálogo de obras está formado por una página que se inicia con un texto sobre el periodo histórico correspondiente acompañado de una ilustración y debajo se suceden los registros de las obras en los cuales los datos bibliográficos van precedidos del número secuencial que las piezas han llevado en la exposición presencial; al pulsar sobre las imágenes o su título, se amplían.

\section{Ex-libris universitatis}

http://busc.usc.es/exlibris/indexlib ris.htm

-Institución organizadora: Rebiun (Red de Bibliotecas Universitarias Españolas).

-Lengua: castellano.

-Fecha de consulta: 03-09-01.

-Contenido: es la primera exposición bibliográfica colectiva de Rebiun (en la que participan 33 universidades españolas, públicas y privadas) y "nace como un proyecto cooperativo con el fin de dar a conocer el importante patrimonio bibliográfico universitario"». La muestra la forman 209 obras: manuscritos e impresos con miniaturas, grabados, mapas y encuadernaciones, entre los siglos $\mathrm{X}$ al XVIII. Es el complemento de otra que tuvo lugar en el Colexio Fonseca de Santiago de Compostela del 28 de septiembre al 31 de octubre de 2000 .
Estamos ante uno de los tipos de exposición más ambiciosos, que se caracteriza por no limitarse a una sola colección, ni a un tema determinado; la riqueza de tipologías documentales, de contenidos y de disciplinas son algunas de las cualidades que la definen. En esta ocasión el afán de erudición aparece reflejado en el título por el empleo del latín y de la palabra "ex-libris", muy unida a la bibliofilia. La portada consta del título y subtítulo (éste en castellano y en los demás idiomas de las comunidades autónomas españolas) separados por un motivo decorativo.

En lo que se refiere al catálogo de obras decir que la exposición se divide en cuatro apartados: Constituciones y estatutos universitarios (11 imágenes de 11 obras), El universo de los códices (44 digitalizaciones de 36 obras), En la cuna de la imprenta (41 fotografías de 38 incunables de Alemania, Italia, Francia, Suiza y España) y La Librería de la universidad (con este nombre se denominaba la biblioteca universitaria hasta el siglo XVIII y es el capítulo más extenso con 134 imágenes de 124 obras). En sus trece apartados (Biblia, textos y exégesis; historia eclesiástica; historia profana y biografías; geografía; lexicografía y gramática; literatura; medicina, veterinaria e historia natural; astrología y matemáticas; bellas artes: arquitectura y artes plásticas, música y danza; arte militar, técnica e industria; filosofía; derecho; y nuevos caminos: la información periódica), se expone una selección de las colecciones que las bibliotecas universitarias guardan como testimonio de su función y de su historia.

Cada uno de estos capítulos se inicia con un texto y seguidamente se disponen los registros de las obras catalogadas, según los siguientes datos: autor, título, lugar, impresor, año, descripción física, localización y al menos una ima- gen digitalizada (que no se puede ampliar) de una página interior, de una ilustración o de la portada.

Otros elementos de interés: Presentación formada por un texto de Darío Villanueva Prieto y por los datos de la comisión técnica de la exposición, universidades participantes y créditos.

-Diseño: la portada juega con elementos de grafías antiguas mientras que en el resto de la exposición se utilizan como recurso principal los frames. El fondo de las páginas es de color blanco y los textos realizados en letras marrones; por su parte, para los títulos se usa el rojo, el ocre y para algunas zonas de las páginas el morado.

\section{Fondo antiguo de la biblio- teca: exposición virtual}

http://www.uma.es/servicios/biblio teca/expo.htm

-Institución organizadora: $B i$ blioteca Universitaria, Universidad de Málaga.

—Lengua: castellano.

-Fecha de consulta: 01-10-01.

-Contenido: alberga una selección de 13 obras antiguas, pertenecientes a la colección bibliográfica del centro organizador, y la exposición se presenta dentro del web de dicha biblioteca. Permite visualizar 16 imágenes de libros y revistas (portadas, páginas interiores y encuadernaciones). Es una muestra reducida que ejemplifica una variedad muy extendida: breve selección de las obras que forman la colección antigua de una determinada biblioteca.

La expresión "fondo antiguo" elegida para el título es una de las más usuales junto a otras como colección o tesoro; colocarla junto a la de "exposición virtual" refleja cierta pretensión de enlazar lo clásico con lo tecnológico y vanguardista. 
Esta página no tiene portada y está constituida básicamente por un catálogo de obras formado por la sucesión de los registros (figura 3). De cada documento aporta: autor, título, edición, lugar, editor, año, descripción física, notas, localización e imagen digitalizada de la portada (que se puede ampliar ocupando toda la pantalla). Cada uno incluye un enlace que completa la información sobre el autor y la obra.

Otros elementos presentes son: texto de presentación por Gregorio García Reche, coordinador de la biblioteca de área, y discurso del presidente de la Sociedad Malagueña de Ciencias con motivo de la inauguración de la sala depositaria del fondo de esta sociedad en la Biblioteca General.

-Diseño: el contenido de la exposición se alberga en un frame dentro de la página de la Biblioteca Universitaria, permaneciendo a la vista el índice general de la biblioteca en la parte superior y el de la universidad en el lado izquierdo (figura 3). Todo el material se dispone en una tabla: en las primeras filas el título y un enlace al texto de presentación, después todos los registros de las obras, cada uno en una fila, ocupada por los datos catalográficos y la imagen de la portada, la cual se dispone en la zona derecha. En último lugar, un enlace al discurso anteriormente comentado.

5. Libros antiguos de matemáticas en la $U L L$ : exposición virtual

http://www.ull.es/bull/lam2000/Ind ex.htm

-Institución organizadora: $B i$ blioteca Universitaria de la Laguna, Facultad de Matemáticas.

-Lengua: castellano.

-Fecha de consulta: 25-09-01.

-Contenido: presenta una selección (en total se exponen 21 obras) de los principales libros antiguos de matemáticas de la Universidad de la Laguna, en su mayoría procedentes de la antigua biblioteca del Instituto de Canarias. Esta exposición se celebró de forma presencial en la Biblioteca Central del Campus de Guajara y tuvo como motivo "2000, año mundial de las matemáticas".

El título elegido define otro de los rasgos de estos recursos virtuales: la escasa imaginación, centrada en destacar la antigüedad y rareza de los fondos. En cuanto a la portada incluye el título, lugar de celebración y el motivo de la exposición (figura 4). El catálogo de obras está organizado en apartados temáticos: Obras medievales, Ediciones de los elementos, Grandes autores, Cálculo infinitesimal, La Enciclopedia, Manuales universitarios, Aritméticas populares y Tablas trigonométricas.

\section{«La expresión 'fon- do antiguo' junto a la de 'exposición vir- tual' refleja cierta pretensión de enla- zar lo clásico con lo tecnológico y van- guardista»}

Sobre las obras aporta un comentario y los siguientes datos: autor, título, lugar, impresor, año, breve texto biográfico, acceso a una imagen digitalizada de la portada y, en ocasiones, un retrato del autor. Se puede visualizar un total de 29 imágenes de los libros, que suelen corresponderse con las portadas. En algunas ocasiones hay un reenvío a la información contenida en los archivos Mac tutor de historia de las matemáticas (representado por un logotipo con las letras $M t$ ) con amplia información gráfica y textual sobre la obra y el autor.

Otros elementos: una página de presentación que, además del índice con los apartados del catálo- go de obras, presenta un breve texto con enlaces a las webs " 2000 , año mundial de las matemáticas" y a la de la Biblioteca Universitaria de la Laguna.

Se incluye también una página para los créditos, con datos sobre el motivo de la exposición, las personas que han participado (organizadores, selección de las obras, catalogación, fotografías y páginas web), dirección de contacto y enlace a los archivos Mac tutor de historia de las matemáticas. Existe otra sección donde se explican cuestiones relacionadas con el copyright de la información de la muestra.

—Diseño: la portada (figura 4) lleva en la parte central una ilustración de un grabado antiguo en el que aparece un libro abierto soportado por dos angelotes que da acceso al resto del catálogo. En la parte superior están el título y subtítulo de la exposición, mientras que abajo figura el lugar y motivo de la muestra. El resto de las páginas presentan una misma composición: los textos en negro, las listas con enlaces en color azul, precedidas de marcas en forma de cuadrado azul relleno y girado. En el ángulo superior izquierdo van colocadas las siglas de la exposición (LAM 2000) y debajo el índice general.

Los apartados del catálogo de obras forman el índice de una página; al acceder a cada uno encontramos un texto introductorio y otro índice con los nombres de los libros, que hacen de términos de acceso a los registros de las obras expuestas. Éstos llevan diferenciados los datos bibliográficos respecto al texto explicativo por un mayor espacio de separación y por distinto tamaño de la letra (menor la del texto). En aquellos casos en los que se incluye un retrato del autor, éste va colocado en el lado izquierdo. 
6. The power of woe, the power of life: images of women in prints from the Renaissance to the present

http://www.lib.virginia.edu/dic/bay ly/women/

-Institución organizadora: University of Virginia.

—Lengua: inglés.

—Fecha de consulta: 08-10-01.

-Contenido: está dedicada a mostrar una selección de obras desde el Renacimiento hasta el siglo XX que contienen imágenes de la mujer. La exposición presencial tuvo lugar en el Museo de Arte Bayly de la University of Virginia del 23 de mayo al 22 de septiembre de 1998. En total se reproducen 38 imágenes de los fondos seleccionados y podemos englobarla dentro de las centradas en las ilustraciones de libros, en este caso puestas al servicio de una determinada iconografía: la imagen de la mujer del XVI en adelante.

El título encuentra su inspiración en los escritos feministas de autores como Henricus Cornelius Aggrippa (siglo XVI) o Cristine de Pizan (XIV), autora que en sus obras da la vuelta a argumentos tradicionales de carácter misógino.

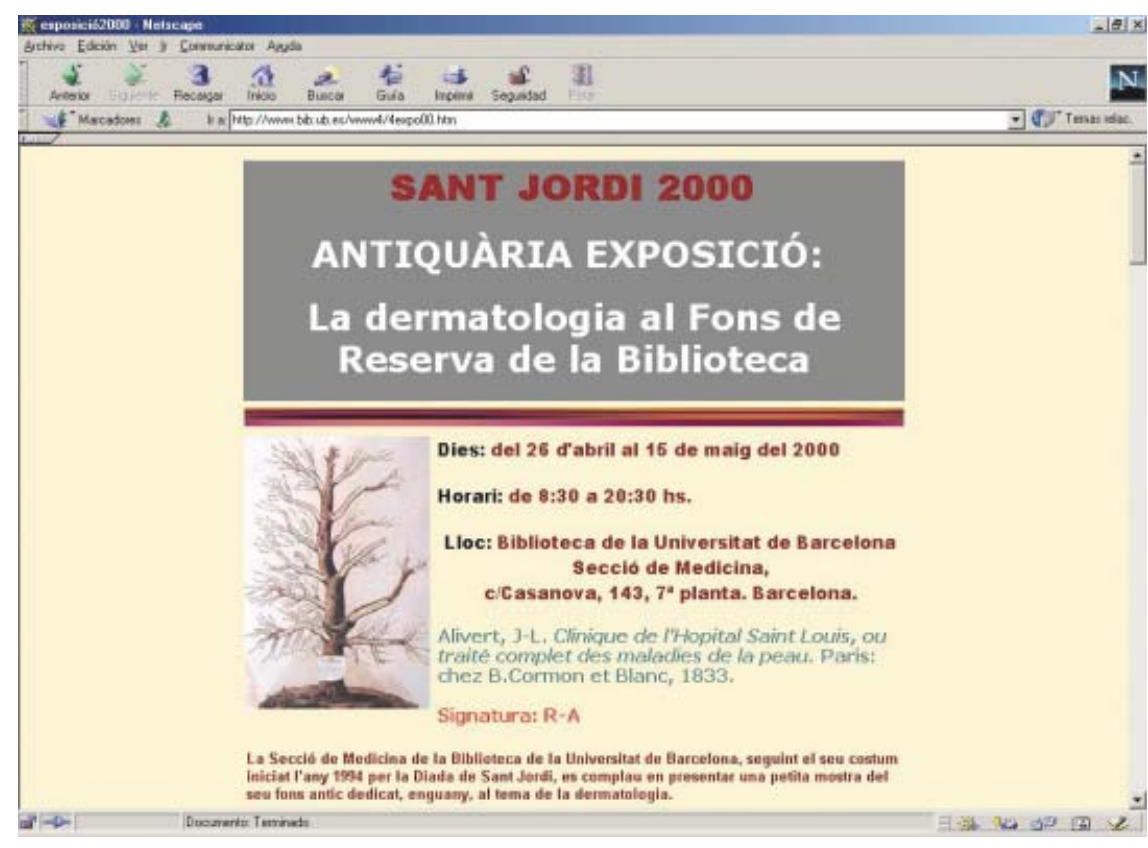

Figura 1

Por su parte, la portada contiene un grabado junto al título y los datos de la muestra presencial. El catálogo de obras recoge las imágenes de los grabados de las obras y, en la mayoría de los casos, van acompañados de un texto de Cristine de Pizan. Las imágenes pueden ampliarse visualizándose también la referencia de la obra y un comentario. Otros elementos que presenta esta web son: una galería virtual y un apartado para los créditos y agradecimientos.

-Diseño: tras la página que hace de portada, accedemos a otra

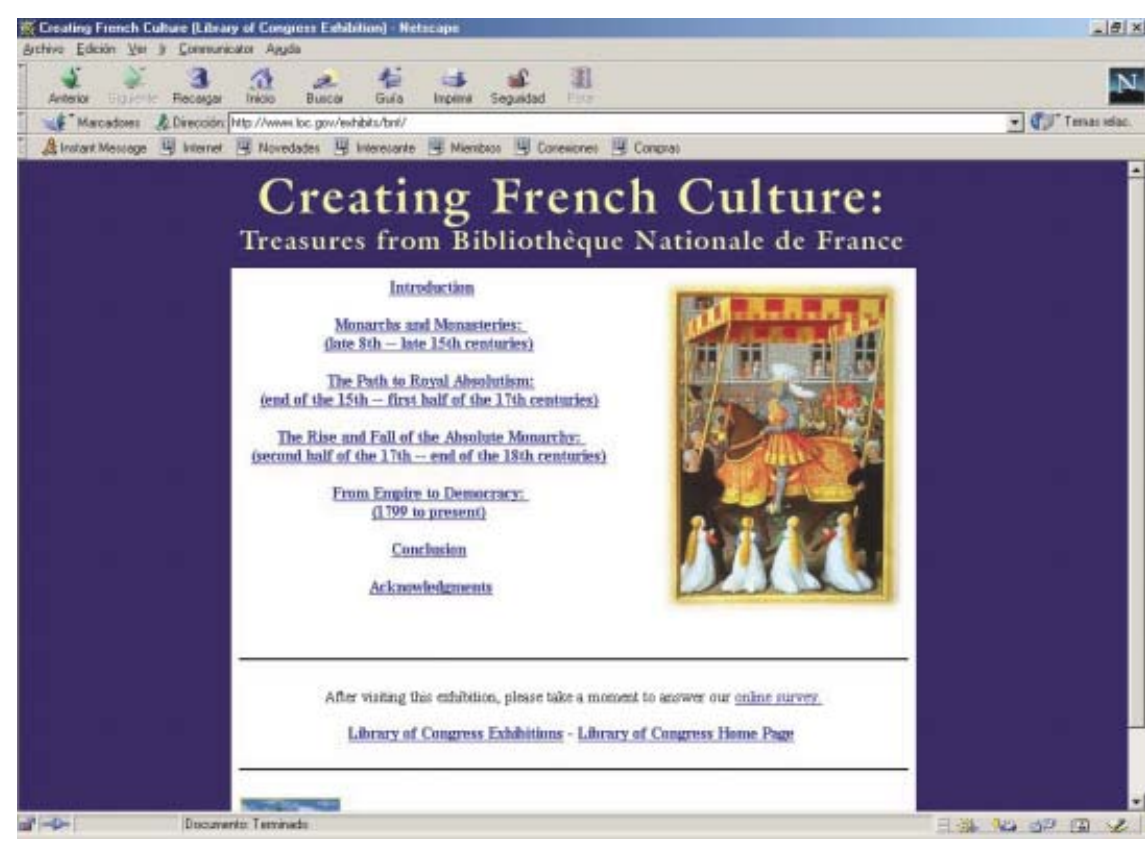

Figura 2 que contiene un plano de la muestra presencial en el que se indican los paramentos en los que están expuestas las obras, (aparecen señaladas por números que, al pulsarlos, permiten acceder a ellas). Junto a este mapa existe también un índice formado por los doce paramentos o muros en los que se distribuyen las obras y a partir del cual también podemos visualizarlas. Está confeccionada como una auténtica muestra virtual y junto a las dos formas descritas para acceder a las obras existe una tercera, la galería virtual, que permite realizar un recorrido virtual. Todos los textos y epígrafes están confeccionados con un cuidado diseño en el que predominan los colores verde y granate.

\section{Le roi Charles $V$ et son temps (1338-1380)}

http://www.bnf.fr/enluminures/acc ueil.shtm

-Institución organizadora: $B i$ bliothèque nationale de France (BNF).

—Lengua: francés.

—Fecha de consulta: 07-10-01.

-Contenido: está dedicada al rey Carlos V y contiene 1.000 ilustraciones de libros antiguos proce- 


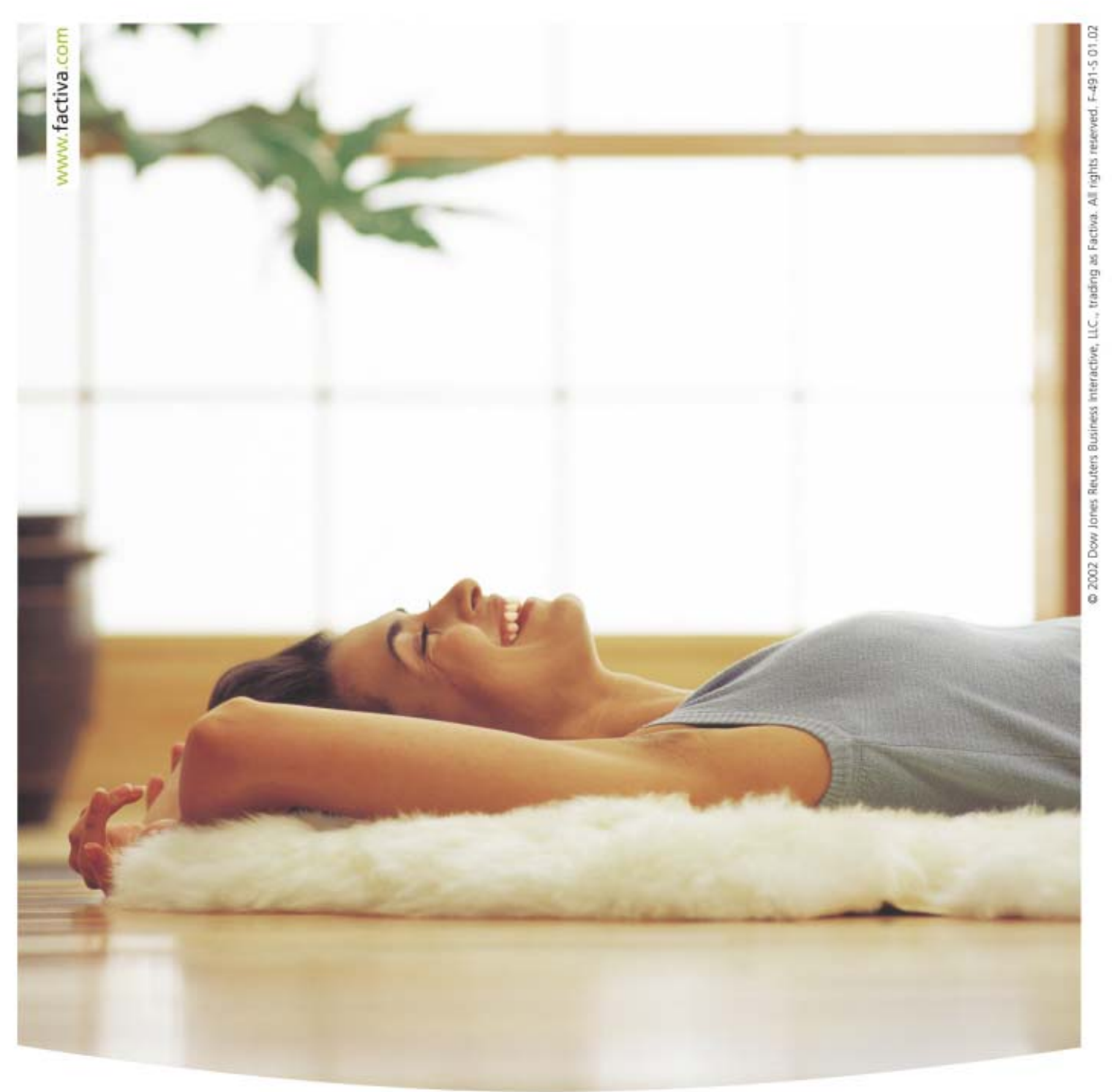

\section{El final de un día. un buen dia. un dia fantástico.}

La presión de un proyecto. Usted lo logró. Datos al alcance de sus manos.

El poder de búsqueda. A su manera. Precisión milimétrica. El mejor contenido.

Dow Jones y Reuters. Dos lideres mundiales. Un nuevo servicio increíble.

Visite www.factiva.com/factiva para más detalles.

Factiva. The basis of a good decision 
dentes del Departamento de Manuscritos de la BNF. Se inicia con una portada decorada con una ilustración de este monarca, junto al título e información complementaria. No se hace referencia al término exposición, pero su diseño y el hecho de estar incluida en la sección de muestras virtuales de este centro bibliotecario prueba la finalidad de la iniciativa.

\section{"La Library of Con- gress es una de las bibliotecas pioneras en la organización de este tipo de eventos»}

El título anuncia que nos encontramos ante un ejemplo de las bien documentadas exposiciones organizadas por la $B N F$ dedicadas a ilustrar un tema monográfico de carácter histórico con fondos bibliográficos. La sección Thèmes podemos considerarla como el catálogo de obras e incluye la siguiente lista: historia, religión, ciencias y técnicas, deportes y diversiones, y diversos. Cada uno de estos términos da acceso a otra relación de subcategorías, subdividida a su vez en una lista de entradas que es la que permite visualizar las imágenes.

Otro elemento de interés es una sección con 17 textos que desarrollan otros tantos temas relacionados con la muestra, los cuales insertan enlaces a las imágenes. Por último, existe una lista de los manuscritos que contienen las ilustraciones y a las que se puede acceder pulsando el nombre de cada manuscrito.

-Diseño: está basado en listas con marcas en forma de esfera, cuyos colores permiten jerarquizar y agrupar la información. Las imágenes son el principal recurso y, como se ha explicado, pueden visualizarse a través de los textos introductorios, los temas y los manuscritos.
8. Rome reborn: the Vatican Library and Renaissance culture

http://www.ibiblio.org/expo/vatica n.exhibit/exhibit/a-vatican_lib/Vat ican_lib.html

-Institución organizadora: $L i$ brary of Congress.

—Lengua: inglés.

-Fecha de consulta: 24-09-01.

-Contenido: en esta exposición se presentan alrededor de 200 obras de la Biblioteca Vaticana: manuscritos, libros, mapas, etc., algunas de las cuales son piezas clave del humanismo y de la herencia greco-romana. Tuvo lugar de forma presencial desde el 8 de enero hasta el 30 de abril de 1993 en el Edificio Jefferson de la Library of Congress, la cual es una de las bibliotecas pioneras en la organización de este tipo de eventos, muchos de ellos destinados a mostrar a sus usuarios grandes colecciones de prestigiosas instituciones lejanas geográficamente.

Esta muestra es la primera de una serie sobre las grandes bibliotecas del mundo y para ello se eligió la Biblioteca Apostólica Vaticana, centro moderno prototípico de la investigación de la cultura occidental. El título elegido destaca muy bien estas cualidades.

Comienza con dos páginas iniciales, una con un texto introductorio sobre la ciudad de Roma Introduction: the city reborn y otra Vatican exhibit main hall, que es en realidad un índice con las secciones de la exposición; el resto de informaciones complementarias se pueden considerar como la portada.

En cuanto al catálogo de obras, la muestra se divide en 9 partes que sólo presentan una selección de las piezas. Para acceder a la totalidad de las obras de la exposición virtual hay que hacerlo a través de los índices; también se incluye un apartado de libros no expuestos. En cada sección (La Biblioteca Vaticana,
Arqueología, Humanismo, Matemáticas, Música, Medicina y biología, Descripción de la naturaleza, Oriente hacia Roma y Roma hacia China) existe un texto de introducción y un índice de términos para acceder a los distintos contenidos temáticos de cada parte. Se ofrecen unas 133 imágenes de códices, manuscritos, mapas, partituras, mapas, etc. Se ha realizado un asiento para cada obra con la descripción bibliográfica, un texto explicativo, la signatura y al menos una imagen que se puede ampliar a un tamaño superior al de la pantalla.

Otros elementos presentes: Índice de objetos, donde aparecen las obras indizadas por los lugares de localización, expresados mediante una signatura que los ubica dentro de su colección; Índice de materias (tanto uno como otro permiten acceder directamente a cada obra); Acerca de la exposición, con un texto explicativo general sobre el contenido de la muestra y su celebración; Introducción, dedicada a exponer de modo breve el papel de Roma en la historia; Historia de la Biblioteca Vaticana y una selección bibliográfica. Estos apartados se complementan con otro que informa sobre la empresa que ha realizado la muestra virtual.

-Diseño: de forma general, el fondo de las páginas es blanco y los textos en negro, organizándose la información en listados o textos indistintamente. Las páginas iniciales Introduction y Main hall contienen bajo el título un dibujo de un fragmento de la columnata de la plaza de San Pedro del Vaticano. Los registros de las obras presentan la información de este modo: en la parte superior el autor y el título, debajo, a la izquierda, la imagen de la obra (que puede ampliarse). Lengua, lugar, año y datos complementarios aparecen junto a la imagen en el ángulo inferior derecho. Por último, en la parte infe- 
rior, junto a la signatura, se sitúa un breve texto explicativo de la obra.

\section{Treasures from Europe's national libraries}

http://portico.bl.uk./gabriel/treasu res/entree.html

-Institución organizadora: bibliotecas nacionales de Europa.

—Lengua: inglés.

-Fecha de consulta: 20-09-01.

- Contenido: los documentos presentados (en total se exponen unas 125 obras) pertenecen a 25 bibliotecas nacionales europeas de las 40 que participan en Gabriel (Gateway to Europe's national libraries), su portal corporativo. El carácter colectivo e internacional definen esta muestra de gran valor representativo, fruto y ejemplo de los esfuerzos que se están realizando en la actualidad por la preservación y difusión del patrimonio bibliográfico mundial. Por ello, una vez más se emplea en el título el fastuoso término "tesoros" unido al de "bibliotecas nacionales", las que cuentan con destacadas colecciones antiguas y las de más peso y tradición en la historia de las bibliotecas, rasgos que hablan de la marcada tendencia culturalista de estas exposiciones.

La portada reproduce el logotipo de la exposición y el índice general. Por su parte, el catálogo de obras es el apartado del índice denominado Tours by subject que presenta las obras agrupadas de dos modos: por tipos (o partes) de los documentos -encuadernaciones, fabricación y decoración del papel, dibujos, manuscritos, postincunables, impresos, etc.- y por materias - arte y arquitectura, biblias, calendarios, geografía, libros de historia, literatura, música y libros religiosos-. Cuando se pulsa sobre el término de uno u otro se despliega un listado con las obras agrupadas bajo esa entrada.

De cada obra se incluye una imagen digitalizada - al hacer clic sobre ella se amplía abriéndose otra pantalla, permitiendo visualizarla a gran tamaño- y los siguientes datos: autor, título, ciudad, cronología, páginas, dimensiones, biblioteca, signatura, páginas en las que se incluye la ima-
El profesional de la información está abierto a todos los bibliotecarios, documentalistas y otros profesionales de la información, así como a las empresas y organizaciones del sector para que puedan exponer sus noticias, productos, servicios, experiencias y opiniones.

Dirigir todas las colaboraciones para publicar a:

El profesional de la información

Apartado 32.280

08080 Barcelona

Fax: +34-934250 029

epi@sarenet.es gen, procedencia, tipo de documento, materia y un texto explicativo.

Otros elementos son: página de bienvenida (que lleva a un libro de firmas, en forma de formulario); listado alfabético de los libros de mayor valor artístico, ordenados por el título, con acceso directo a los registros del catálogo; un apartado de índices con las opciones: bibliotecas nacionales (ordenadas por países), títulos de las obras, creadores/contribuidores y fecha de publicación. Los términos de los índices acceden directamente a los registros de las obras y además incluye un enlace a un formulario para realizar búsquedas en $G a$ briel. Por último, recoge una sección con obras "nuevas" que se van incorporado a la exposición.

-Diseño: en todas las páginas se emplea el fondo blanco y las letras en azul (el color rojo se usa en las letras que separan las distintas partes de los índices alfabéticos y en algunas del título de la exposición, colocado en la portada y en el logotipo); el índice general está en la parte superior formado por el logotipo, el título de la exposición y los términos en disposición horizontal sobre un fondo azul, el cual, al pulsarlos, cambia a blanco.

Un recurso destacado es el empleo de listas para presentar la información: los términos van precedidos de una marca en forma de punta de flecha y en la parte superior izquierda, como motivo decorativo, ilustraciones (o fragmentos) de diferentes obras, enmarcadas por una moldura dorada.

En la portada se reproduce un mapa de Europa en color azul dentro de un rectángulo, todo sobre un fondo blanco mientras que en la parte inferior van los términos del índice general en disposición horizontal. Dentro del catálogo de obras se dedica una página propia para cada pieza con el título de la 
obra, la biblioteca a la que pertenece y el país, todo en la parte superior; debajo se sitúan las imágenes de las obras. A continuación se incluyen los datos catalográficos, la procedencia, el tipo de documento y la materia. En la parte inferior, separado por una línea, el texto explicativo y por último en el ángulo inferior derecho se encuentra el logotipo y el título de la exposición.

\section{Treasures from two mi- lennia. Fifty treasures from Glas- gow University Library}

http://special.lib.gla.ac.uk/exhibns /treasures/index.html

-Institución organizadora: Glasgow University Library.

—Lengua: inglés.

-Fecha de consulta: 06-10-01.

-Contenido: para celebrar el aniversario de la fundación de esta universidad en 1451 gracias a una bula del Papa Nicolás, se organiza está exposición dedicada a mostrar 50 obras (de cada una se muestra una imagen) del fondo antiguo de su biblioteca, entre ellas encontramos papiros, códices, grabados, impresos, mapas, etc. La página se inicia con el título y la introducción, no teniendo portada propiamente dicha.

En el título, gracias a los términos en los cuales se expresa, se observa la intención de recuperar el valor y prestigio del libro frente a la amenaza que suponen los nuevos soportes en la era de las nuevas tecnologías; para algunos están

Libros antiguos de matemáticas en la $U L L$ Exposición virtual

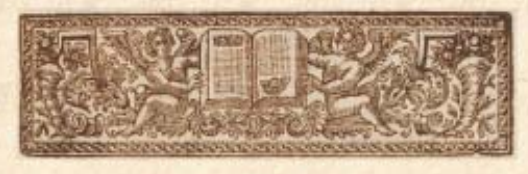

Biblioteca Central

Campus de Guajara

2000 Ano Mundial de las Matematicas

Figura 4

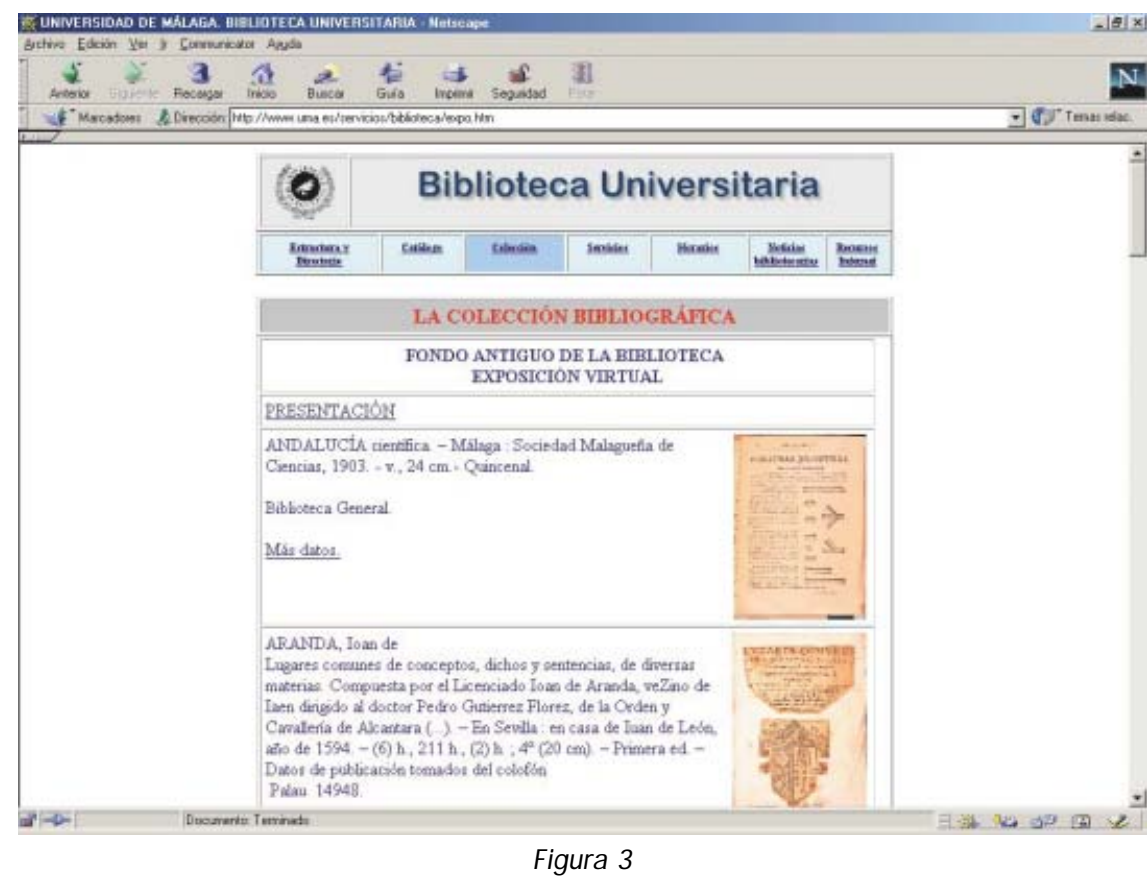

erosionando progresivamente la posición destacada que el libro tuvo en la era tipográfica.

Al catálogo de obras se puede acceder desde un índice cronológico o desde uno de materias y formatos. De cada obra se presenta una imagen ampliable, título, cronología, signatura y texto descriptivo. Otro elemento que se puede encontrar es el texto de introducción a cargo de David Weston, conservador del Departamento de Colecciones Especiales de la universidad.

-Diseño: está acorde con la web general de la biblioteca, el índice de la cual aparece en la parte superior. La información de la exposición se alberga en dos páginas, una para la introducción y otra para las obras, con dos índices: cronológico y de materias, que permiten acceder mediante anclas a las obras, dispuestas sucesivamente en la misma página. Cada apartado temático o cronológico se inicia con un epígrafe precedido del fragmento de una ilustración.

\section{Conclusiones}

De las 71 webs recopiladas 37 han sido organizadas por instituciones de los EUA, 5 de Canadá y 29 de Europa (12 Gran Bretaña, 7 España, 6 Francia, 2 Dinamarca, 1 Holanda y 1 el conjunto de bibliotecas nacionales europeas). En 39 de ellas se hace alusión a la correspondiente exposición presencial de la que es complemento la virtual y en 32 no se hace ninguna mención a la posible versión presencial.

Las grandes bibliotecas, entre las que se encuentran las nacionales, han incluido en sus sitios web un apartado dedicado a las exposiciones virtuales organizadas, donde tienen cabida muestras de todo tipo, entre ellas las de fondo antiguo. Destacan la Library of Congress, la Bibliothèque nationale de France y la British Library. Los documentos que las integran en su versión online no presentan el texto completo, a lo sumo unas cuantas páginas y en muchas ocasiones una sola, casi siempre seleccionadas por su valor estético (ilustraciones, miniaturas, grabados, etc.). Como excepción, hemos localizado algunas muestras dedicadas a un único libro, en cuyo caso sí se reproduce entero. 


\section{The Paper Filing Company ${ }^{\oplus}$}

ZyLAB ofrece sus servicios a sus usuarios de todo el mundo desde sus oficinas en Holanda, Estados Unidos, Alemania, España, Francia, Singapur y Australia. Originariamente desde Chicago (fundada en 1983), ZyLAB se dedica desde 1991 a desarrollar soluciones para buscar y compartir información de documentos en papel. Desde 1995 todo el desarrollo del software se realiza en las oficinas centrales de Amsterdam, Holanda.

\begin{tabular}{ll}
\multicolumn{2}{c}{ Solución escalable y robusta } \\
Trabajo en grupo: & ZyIMAGE \\
Departamental: & ZyIMAGE Webserver \\
Corporativa: & ZyIMAGE Enterprise Webserver
\end{tabular}
Corporativa:

Más información y formación ZyLAB organiza regularmente seminarios y sesiones de formación. Adicionalmente dispone de CD's de demo. Además, se pueden generar CD's con demostraciones personalizadas, utilizando documentos propios de cada cliente potencial.

\section{Principales socios}

ZyLAB trabaja estrechamente junto a socios reconocidos, como:

$$
\begin{aligned}
& \text { - Microsoft } \\
& \text { - Adobe } \\
& \text { - Océ Find Logic } \\
& \text { - Sharp } \\
& \text { - Fujitsu } \\
& \text { - Ricoh / Nashuatec } \\
& \text { - Xerox }
\end{aligned}
$$

\section{Principales referencias}

Globalmente, la tecnología de ZyLAB ofrece acceso a los más grandes archivos, entre otros:

- Tribunales de Guerra y Tribunal Internacional de Justicia (tribunales para Yugoslavia y Rwanda)

- Investigaciones de Fraudes Financieros (EC's OLAF, departamentos de Auditoria Forense de KPMG y

PriceWaterhouseCoopers)

- Diversas Policías y agencias de inteligencia

- Casos legales complejos (casos O.J. Simpson y Dover) - Multinacionales (AKZO Nobel, Glaxo Wellcome, Dell

Computers, Lloyd's of London, Banco de Indonesia)

- Medios de comunicación (BBC, Disney World Hong Kong) (existen otras muchas referencias disponibles; no dude en consultar)

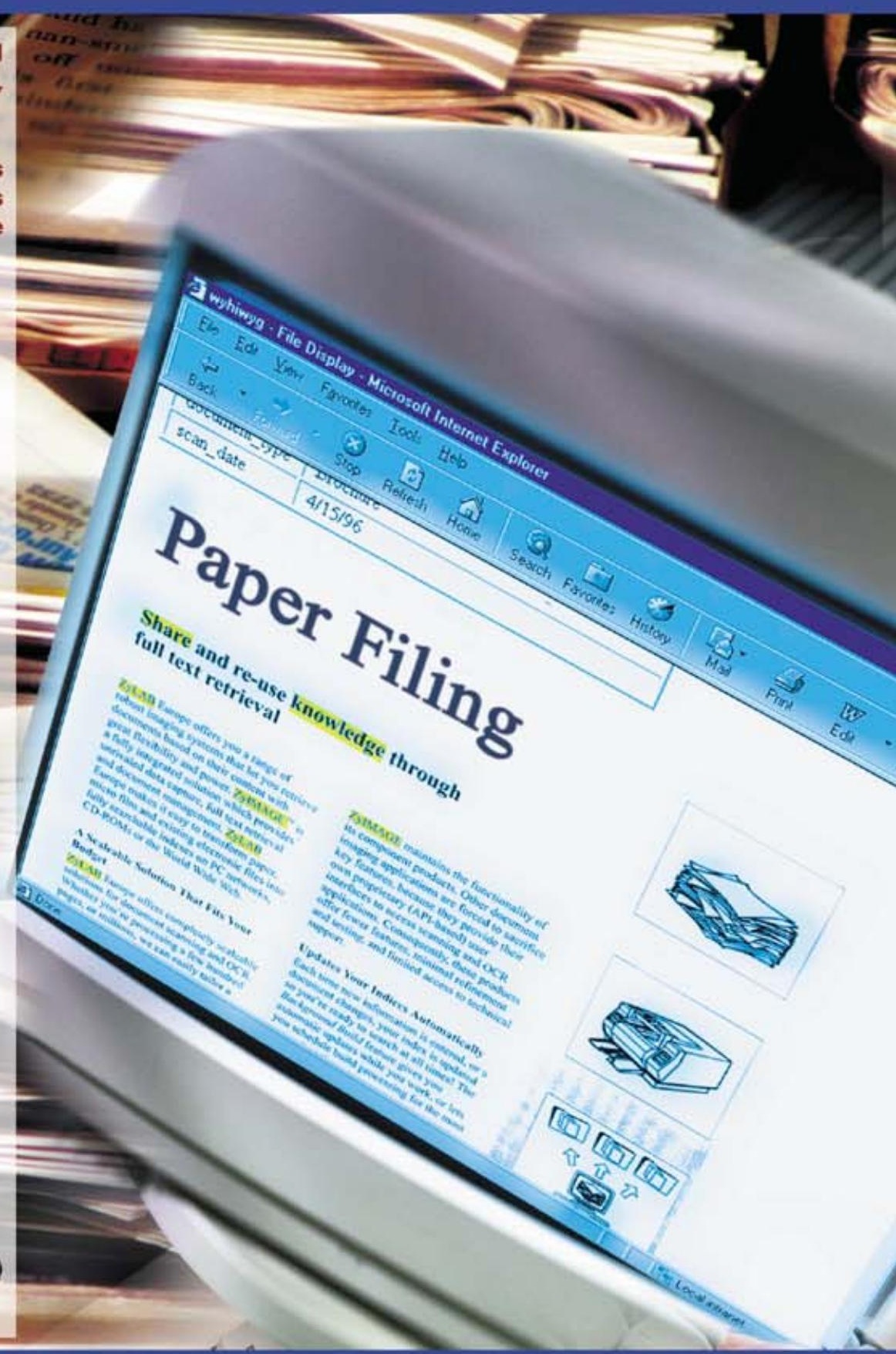

\section{The new way of paper filing}

\section{Contacto:}

ZyLAB Iberia

Zurbano, 83-3A

28003 Madrid

Teléfono: +34914185811

Fax: +34913990514

Web: www.zylab.es

e-mail: javier@zylab.nl

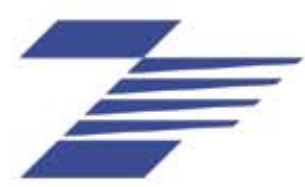

ZyLAB Iberia

Avenida Gaudi, 33-35, pral. 2a

08025 Barcelona

Teléfono: +34934366945

Web: www.zylab.es

e-mail: jesus@zylab.nl 
Casi todas estas webs aparecen ligadas al concepto de "exposición virtual", empleándose esta expresión en el título, o en los textos introductorios que explican el contenido y los objetivos de la muestra. Sin embargo, gran parte de estas exposiciones son reproducción o adaptación mecánica de los catálogos y presentan un enfoque muy clásico. Este carácter tradicional se refleja también en la redacción de los títulos, pues tras un análisis de ellos hemos comprobado cómo se repiten expresiones que evidencian una enorme querencia histórico cultural, tales como tesoros o libros raros (en 15 ocasiones), fondo o colecciones especiales, antiguas (en 20).

En pocos casos se utiliza la expresión catálogo online. Nos parece que todas responden mejor al concepto de catálogo de exposición: hemos comprobado que su contenido, estructura y características son muy semejantes a las de este tipo de documentos. Por ejemplo, existe cierto paralelismo en cuanto a la extensión entre estas webs y los catálogos impresos de exposiciones: los hay que sólo ocupan una página (coinciden con los programas de mano, trípticos, folletos) hasta los más voluminosos que contienen cientos de obras, textos complementarios y enlaces (semejantes a los completos estudios que dan lugar a interesantes monografías realizadas a raíz de la catalogación de las obras de una exposición). También coinciden en cuidar la presentación y la estética, fruto de atractivos diseños.

Consideramos que un nombre más apropiado para denominarlas sería el de catálogos virtuales de exposiciones ya que, aunque aparecen bajo la denominación de exposiciones, no permiten algo que es esencial en una de tipo presencial: realizar una exploración a través del paseo por los objetos tridimensionales. Por eso Belcher defi- ne la muestra presencial como "un arte medioambiental que ofrece una gama de experiencias que pueden estimular los sentidos. Utiliza no sólo la forma y el espacio, sino también el contorno, el color, la luz, la textura"".

Sin embargo, al igual que los catálogos impresos de exposiciones, estos recursos en línea cumplen la función de facilitar un mejor aprovechamiento de la visita preparándola con antelación. También permiten acceder a piezas y colecciones privadas o poco accesibles que de otro modo sería difícil conocer pero, sobre todo, coinciden en el importante papel que desempeñan una vez que la exposición presencial ha finalizado pues la prolongan en el tiempo.

A diferencia de los catálogos impresos, los virtuales no permiten ser utilizados durante el recorrido por la exposición real, como guía y ayuda para la visita (salvo que se impriman, por supuesto). No obstante pueden resolver los problemas de localización, disponibilidad y conservación que existen con los impresos, motivados por la dificultad que tienen algunas bibliotecas para controlar y poner a disposición del público parte de estos documentos, que por ser material menor (folletos, programas) con frecuencia no forman parte del material a catalogar.

El patrimonio bibliográfico de más antigüedad conservado en los centros bibliotecarios es muy apropiado para incluirlo en proyectos como estas exposiciones o catálogos virtuales pues facilitan su difusión, conocimiento y acercamiento a una mayor parte de usuarios. Además, constituyen una nueva y atractiva forma de acceder a los libros antiguos. Entre los distintos usos de estas webs subrayamos su empleo como recurso para la docencia de las asignaturas relacionadas con el fondo antiguo en los actuales planes de estudio de biblio- teconomía y documentación. La enseñanza de estas materias se ve obstaculizada, en muchas ocasiones, por la imposibilidad de disponer de obras originales e incluso de reproducciones. Por esta razón los proyectos de este tipo accesibles a través de la Red pueden paliar el problema.

\section{Notas}

1. Diego Erles, Jesús de; Velasco de la Peña, Esperanza. "Recursos en internet sobre el libro antiguo en Europa". En: Scire, 1999, v. 5, n. 1, pp. 91-103.

2. Velasco de la Peña, Esperanza; Merlo Vega, José Antonio. Nuevas formas para el acceso al libro antiguo. Consultado en: 06-06-01. http://exlibris.usal.es/merlo/escritos/aib.htm

3. Codina, Lluís. "Parámetros e indicadores de calidad para la evaluación de recursos digitales". En: VII Jornadas españolas de documentación, 2000, pp. 135-144.

Los parámetros tenidos en cuenta han sido: $\mathrm{Pa}$ rámetro 2, contenido: valor intrínseco de la información. Parámetro 3, acceso a la información. Parámetro 4, ergonomía.

4. Las últimas consultas realizadas han sido en septiembre de 2001.

5. Las direcciones y títulos de las exposiciones virtuales no incluidas en el análisis las indicamos en el cuadro webgrafía.

6. Cuando no se dice lo contrario se entiende que las imágenes se presentan en color.

7. González, Toni. "La biblioteca de la Universitat de Barcelona acoge una exposición. La dermatología, una especialidad con varios siglos de trayectoria". En: Diariomedico.com, jueves 11 de mayo de 2000. Consultado en: 1903-01.

http://www.diariomedico.com/entorno/home.ht $m l$

8. La biblioteca de la Universidad Complutense en la exposición "Ex libris universitatis". Consultado en: 19-03-01.

http://www.ucm.es/BUCM/Exlibrisuniversitatis.htm

9. Belcher, Michael. Organización y diseño de exposiciones: su relación con el museo. Gijón: Trea, 1994. Isbn 84-87733-54-9.

José Luis Herrera Morillas. Universidad de Extremadura.

Tel.: +34924259 910;

fax: 924286401

jlhermor@alcazaba.unex.es 